\title{
INTERNATIONAL STUDENTS' PERCEPTIONS OF COMMUNICATION CHALLENGES IN ENGLISH MEDIUM INSTRUCTION
}

\author{
Nedka Dimitrova ${ }^{1}$
}

\begin{abstract}
The main research objective of this corpus-based study is to identify communication challenges faced by international students of business management in the context of using English as a Medium of Instruction (EMI) in a non-English speaking country. It attempts to gain an insight on learners' perceptions of intercultural communication (ICC) barriers, associated with their native language and cultural background in the process of developing academic and cultural competences. Quantitative data was derived through a small specialised corpus, comprising of 13,896 words, constructed from 47 students' reflective essays. The research assumptions and analysis of discourse were based on the model of the six Stumbling Blocks in Intercultural Communication developed by LaRay M. Barna (1994). The evidence from the study suggests that differences in verbal and non-verbal language expressions are perceived as a more significant communication block, due to the fact that they seem to be attributed with clear self-awareness of the problem. The results also indicate that language differences and cultural ambiguity are more significantly expressed by students raised and educated in higher context cultures, sharing more collectivist values. To handle these issues in EMI, an approach to self-conscious actions and efforts is needed from all participants in the process to develop linguistic and intercultural communication competence (ICCC).
\end{abstract}

Keywords: intercultural communication, English as a Medium of Instruction, academic discourse, corpus linguistics, stumbling blocks

\section{Introduction}

The objective of this corpus-based research is to identify linguistic patterns associated with some potential expectations and perceptions of intercultural communication barriers which international students of business management may hold in the context of using English as a main language of study in an Anglophone university based in South East Europe. A combination of quantitative and qualitative approaches are used in the analysis of data in an attempt to provide a comprehensive review of particular features of discourse systems which influence classroom interaction through EMI.

1. PhD Candidate at the Department of English Studies, Shumen University, Shumen, Bulgaria; Intercultural awareness and Business Communication lecturer at Varna University of Management, Varna, Bulgaria, e-mail: nedka.dimitrova@vumk.eu 
Along with the fast acceleration of EMI, there emerges the question of how the global 'language of higher education' (Coleman, 2006) affects communication process and the expected student's behaviour in academic environment with regard to the context of debates and common concerns about national identity, access to education and significantly differentiating factors related to the cultural, political and economic impact of the phenomenon. Promoting communicative competence should be seen as a primary concern in the challenging context of EMI and the main prerequisite for learning success, hence focusing attention on international undergraduates' expectations and perceptions of communication challenges can raise not only educators' awareness of students' communication needs and appropriate communication strategies for syllabus design but also of their own communicative competence as an essential skill needed to encourage and engage learners. Adopting a communicative approach in teaching and learning should be considered an indispensable condition for blending the main components of communicative competence, including grammatical accuracy, sociolinguistic knowledge of rules functioning in language use and discourse, and strategic competence associated with the communicative performance of verbal and non-verbal compensatory mechanisms used in a case of grammatical or sociolinguistic failure (Canale \& Swain, 1980, p. 27). Along with Canale and Swain's concept of communicative competence, there has been an increasing concern overmetacognitive strategies and the ability used to facilitate theinterplay between the knowledge of language and the perceptual functions of language use (Bachman \& Palmer, 2010). Celce, Murcia, Dornyei and Thurrell (1995) continued the debate about communicative competence, highlighting the role of discourse competence within the framework of assessment criteria for language proficiency and suggesting several important components forming sociocultural competence, including social contextual factors, stylistic appropriateness, cultural factors and non-verbal communicative factors (p.24). The complex nexus of sociocultural differences and diversity of identities in Anglophone universities suggest a critical need for strategic and discourse competences, however these could not be based on the milestone of a native speaker model after the global spread of English as a lingua franca in the beginning of the new century. The acquisition of knowledge and information through English requires a shift to a more culturally aware approach towards critical thinking needed to elicit and interpret information in the complex context of EMI. ICC skills, related to "identity-sensitive knowledge, ethnorelative attitudes and adaptive interaction skills" (Ting-Toomey \& Dorjee, 2019, p. 4) could facilitate the process of adjusting to other participants' verbal or non-verbal behaviour and appropriately encode and decode messages transmitted during exchange of information for mutual understanding and successful communication outcome. Quite recently the strategic role of English as a global language has drawn the attention of corpus linguists, who are interested in examining various aspects 
of the context (Biber, 2006; Björkman 2017; Chang, 2010; Coleman, 2006; Evans, \& Morrison, 2011; Jensen, Denver, Mees \& Werther, 2013; Wilkinson, 2013) with a focus on specific research questions related to discursive markers, practices and principles of bilingualism. Differences in classroom discourse features reflect cultural variations of values and norms influencing the process of learning and perceptions of education practices, therefore comparing crosscultural corpora provides reliable information about the impact of particular factors on participants' behaviour and performance in EMI (Moreno, 2008).

\section{Previous research}

According to Handford (2015), corpus linguistics (CL) could be defined as a methodology in the field of discourse analysis, which relies on qualitative and quantitative approaches to study various language aspects through the means of computer software. McEnery and Hardie (2012), Bhatia, Flowerdew and Jones (2008), and Gee and Handford (2012) have sought to address new ways and approaches with a focus on the social context in transaction of information and making meaning. In the same vein, intercultural and crosscultural communication have been an object of research in CL by Biber, Conrad \& Reppen (1998); O'Keeffe \& Adolphs (2008) and Handford (2014), exploring the concept of cultural identity as a fixed parameter rather than elicited from discourse. Handford draws on Collier and Thomas's (1988) interpretation of managing multiple cultural identities which are negotiated in ICC, to study discursive questions related to cultural identities and communication through a purposeful application of corpus methods relying on ethnographically informed, smaller size specialised corpora. Seidlhofer, Breiteneder \& Pitzl (2006) suggest that L2 speakers of English are likely to transfer their previous experience in the process of language production, thus avoiding the use of idiomatic expressions. Similarly, a corpus-based study by Todorova (2017) exploring the metaphoric transfer of advertising printed messages, has argued that receivers who lack awareness of the intended cultural meaning are likely to misunderstand the main idea or even to develop negative attitudes to the product in question. A multimodal analysis of media headlines by Nedelcheva (2017) has shown that sharing information within a particular society involves references of common cultural knowledge associated with recurring linguistic patterns which ensue specific expectations and interpretations of the messages.

Ting-Toomey and Dorjee (2019, p. 22) define ICC as "The symbolic exchange process whereby individuals from two (or more) different cultural communities attempt to negotiate shared meanings in an interactive situation and in a larger sociocultural-macro environment", in which sharing of meaning is influenced by individual expectations based on cultural perceptions. Communication perception as a process of quick identification of symbols arranged in a specific 
structure is interpreted according to people's expectations (Ting-Toomey \& Chung, 2012) and can cause communication failure due to problems in use of language, different styles of expression and different values, hence negotiation of meaning should involve clarification of identity, content and relationship which happens in a specific physical and psychological socio-cultural context of interaction in an Anglophone university. It can therefore be assumed that Dearden's $(2014$, p. 2) definition of EMI as "The use of the English language to teach academic subjects in countries or jurisdictions where the first language (L1) of the majority of the population is not English" would call into question its effectiveness, drawing attention to the communication challenges it imposes to students and educators. In this respect, Hofstede's (1986, p. 316) understanding of language (as) an obstinate vehicle of culture suggests that words should fit in a cultural framework in order to prevent from loss of meaning. In the light of Hofstede's cultural classification typology (1980) and his concept of the degree to which societies tolerate social injustice, depend on the group and strive for achievement, it can be assumed that a significant barrier of communication in EMI can arise from students' expectations and the linguistic low-context nature of the English language associated with more individualist, inductive thinking and experimentation, which contrasts with the culturally adopted deductive and more reflective thinking of students from collectivist cultures. Hall's $(1966,1977)$ classic theory of high and low context helps further to elucidate differencies in language expression of cultural values and behavioural patterns of international students in HE through the concept of high-context culture messages which tend to be transmitted in a context reflecting the individual sense of tight group belonging, characterised with physical symbols, lots of metaphor and nonverbals. In contrast, low-context culture messages seem more concise with a focus on the verbal rather than on the nonverbal part, ruled by more open relationships and flexible group belonging. Following this, it can be assumed that the low-context nature of English as a medium of learning and socialisation in EMI, might raise controversial interpretations of its functionality in non-English speaking environment and a threatening means to exert cultural influence. To understand the various perceptions of communication challenges that exist among international student, we can take an account of LaRay Barna's model of six stumbling blocks (1994) which points to communication challenges facing people in international settings and the potential rejection they might experience as a result from failure in the exchange of ideas and information. Western trappings, according to Barna, are hidden below the superficial similarity in the style of dress, greeting rituals and use of English for socialising, "Without being alert to possible underlying differences and the need to learn new rules for functioning, persons going from one city to the other will be in immediate trouble even when taking on such simple roles as pedestrian or driver" (p. 338), that is to say, lack of sociolinguistic and 
strategic competence in English language can lead to misunderstanding and frustration on the ICC stage as a result from withdrawal and defensiveness in the process of communication, related to higher levels of anxiety and stress. Barna suggests the possibility that assumptions of similarity, language differences, nonverbal misinterpretations, stereotypes, tendency to evaluate and high levels of anxiety to blend in a cultural shock, and thus to cause misinterpretation of the seemingly threatening environment (p. 343). Those negative physiological and psychological effects could be handled in EMI through self-conscious actions and efforts from all participants in the process to develop linguistic and sociocultural knowledge, in order to enhance their communicative and intercultural communication competence (ICCC). Byram, Nichols and Stevens (2001, p.7) have argued that developing intercultural skills and knowledge should be built over the values people possess as a result from their belonging to various social groups, without changing their values but making "them explicit and conscious in any evaluative response to others". This complex character of the global context of EMI forces the need to discuss the phenomenon not only as a key tool of teaching and learning but also as an indispensable ICC driver, enabling students' cognitive, affective and behavioural skills.

\subsection{Research questions}

Taking into account the limitations of the early stage of intercultural experience and development of ICC skills and competence of the informants, this research will seek to address the following questions:

- What are the most common international students' perceptions of intercultural communication barriers in multicultural learning environment?

- What are the consequences of communication issues on international students' academic performance?

- What educational implications could be made for developing strategic competence of international students?

\subsection{Research hypotheses}

Drawing upon Barna's model of the Six Stumbling Blocks and assuming that making meaning in EMI is established through English as a secondary system of communication, it can be supposed that differences in perceptions of lexicogrammatical features of the language will be identified as the most important communication block by the students, due to the fact that they seem to be attributed with clear self-awareness. In particular, the hypotheses which will be tested are that: 
Hypothesis 1: Language differences in lexico-grammatical features of the language will be centrally focused and perceived as the main communication barrier by international students in intercultural learning environments.

Hypothesis 2: Barriers associated with the unconscious assumption of similarity, stereotyping, tendency to evaluate and cultural shock will have a less significant effect on students' perceptions of communication barriers.

Based on Hall's theory of high and low context, it can be assumed that adjustment and learning in a new academic discourse system of EMI would be more problematic for international students whose identities confront to a greater degree with the elements of the new discourse transmitted through the means of English as a main language of communication. It is possible, therefore, to make the following hypothetical statement:

Hypothesis 3: Perceptions of language differences and cultural ambiguity and associated expectations for communication barriers will be more significantly expressed by students raised and educated in higher context cultures sharing values of collectivism and hierarchical relationships.

\section{Research methodology}

To identify the most common barriers in the interdiscourses of ICC and EMI, the current research applies a combination of corpus-based approach and discourse analysis, which help to investigate the imprinted language stance projecting students' expectations and perceptions in the process of learning. This situated meaning approach to discourse analysis suggested by Gee 2010 (p. 151) facilitates the differentiation between the general and the specific meanings of words in the given context based on previous experience and shared knowledge of the students. Searching for correlations (or collocations) of linguistic patterns is essential to understand the mix of social identities enacted in particular messages.

\subsection{Research procedure}

A collection of students' handwritten work was converted into computer-readable format and uploaded to the Sketch Engine system (https://www.sketchengine. $\mathrm{eu} /$ ) in order to build a language corpus for the purposes of the current research. To answer our first research question and to test Hypotheses 1 and Hypothesis 2, word-sense lexical categories, such as language and culture, were identified through key words and frequency profiling. With the aim of representativeness, the English Web Corpus (en Ten Ten 2013) was used as a normative corpus of reference. Four smaller subcorpora were created further to make differentiation between cultural groups in order to find evidence of significantly different frequency of features supporting Hypothesis 3. The collocational behaviour of 
the most frequent lexical units was explored through the Word Sketch function which was used to discover their collocates in the context, to trace concordance lines providing information for qualitative analysis of situated meaning through semantic prosody and to make inferences associated with specific positive or negative meanings. A qualitative approach based on the corpus findings was used consequently to interpret the information and to answer questions 2 and 3.

\subsection{Source of data}

The primary data was collected in December, 2018, from 47 first-year undergraduates' short reflective essays, written in a formal classroom environment as one of three compulsory tasks in a course portfolio, intended for summative assessment of students' communication skills and knowledge of the discipline at the end of an obligatory course in Business communication.

\subsection{Demographic profile of the informants}

Of the 47 informants, 22 male and 25 female students from 20 countries, with an age range from 18 to 24 contributed to the collection of written material for building the corpus. Only two Erasmus + students had previously attended a Business communication course in their home universities and 45 undergraduates were receiving the course for the first time. The 27 international Erasmus + exchange students and 20 regularly enrolled students had been attending a business or a hospitality management degree programme in an Anglophone business school in Eastern Europe for three months. The programmes of study conducted in a partnership with a British university were following specific curriculum requirements and standards, including English as the only medium of formal instruction. The informants were divided into four groups based on the mapping of cultural distance between geographical regions and their orientation to specific cultural values as defined by House, Hanges, Javidan, Dorfman and Gupta (2004). The data was collected from representatives of 8 cultural clusters on the map, which were further grouped into East Europe, West Europe, Africa and Middle East, and Confucian and Southern Asia. Out of the 47 students, 5 were bilingual and only 3 were using a version of English as their native language (Zimbabwean and Nigerian English).

\subsection{Type and size of corpus}

A collection of 47 non-English speaking undergraduates' reflective essays was compiled to create a purpose-built specialised mini corpus of 13,896 words, addressing the questions of the study. The essay of 200 to 300 word-length was assigned as a written task in a final Business communication course portfolio, following the conventions of academic writing in English and the 
genre associated with business communication as a subject field. To facilitate automatic retrieval of information and to ensure readability of specific linguistic and grammatical features needed for text analysis, the corpus data was tagged for parts of speech and lemmatised by the default English Tree Tagger part-ofspeech (PoS) tagset available in English corpora on Sketch Engine with some modifications (Marcus, Santorini \& Marcinkiewicz, 1993).

\section{Findings}

To test Hypothesis 1, it was considered that quantitative measures of key word and term frequency would usefully supplement and extend the content analysis through processing of PoS tagged and lemmatised tokens in order to model the topic and to identify the most common instances of words and phrases indicating students' perceptions of intercultural communication barriers.

\subsection{Frequency and keyword profile}

To ensure representativeness and test reliability of comparison, we referred to a larger corpus, the English Web 2013, in order to provide a text norm for frequency and key word profiling of the specialised sample corpus through a 19-million word collection of various types of internet texts, accessed through the Sketch Engine query system. The exploration of the unique features of the learners' perceptions of ICC barriers in the focus corpus showed that verbal and non-verbal language barriers were centrally focused and perceived as the main communication barrier. Pinpointing single and multiword key items revealed a trend towards a higher frequency of key words and multiword expressions of language barriers matching the target topic of communication in EMI (Table 1 \& Table 2).

Table 1.

Table 2.

The Most Frequent Key Words

The Most Frequent Key Terms

\begin{tabular}{|llllllllll|}
\hline & Keywords & $\begin{array}{l}\text { Keyness } \\
\text { Score }\end{array}$ & Freq & Ref freq & & Key terms & $\begin{array}{l}\text { Keyness } \\
\text { Score }\end{array}$ & Freq & $\begin{array}{l}\text { Ref } \\
\text { freq }\end{array}$ \\
\hline 1 & I & 2.990 & 353 & 174439711 & 1 & body language & 235.950 & 12 & 550 \\
2 & we & 3.790 & 208 & 81207116 & 2 & university group & 714.010 & 11 & 1 \\
3 & not & 2.050 & 192 & 138463385 & 3 & $\begin{array}{l}\text { language } \\
\text { barrier }\end{array}$ & 475.060 & 11 & 121 \\
4 & barrier & 392.510 & 157 & 568973 & 4 & $\begin{array}{l}\text { english } \\
\text { proficiency }\end{array}$ & 429.510 & 9 & 87 \\
5 & different & 19.890 & 145 & 10764033 & 5 & group work & 299.100 & 8 & 177 \\
6 & other & 4.730 & 126 & 39362901 & 6 & different culture & 336.440 & 7 & 85 \\
7 & communication & 83.340 & 120 & 2107307 & 7 & different level & 266.210 & 7 & 170 \\
8 & group & 18.490 & 115 & 9179578 & 8 & $\begin{array}{l}\text { communication } \\
\text { barrier }\end{array}$ & 372.830 & 6 & 12
\end{tabular}




\begin{tabular}{|c|c|c|c|c|c|c|c|c|c|}
\hline & Keywords & $\begin{array}{l}\text { Keyness } \\
\text { Score }\end{array}$ & Freq & Ref freq & & Key terms & $\begin{array}{l}\text { Keyness } \\
\text { Score }\end{array}$ & Freq & $\begin{array}{l}\text { Ref } \\
\text { freq }\end{array}$ \\
\hline 9 & do & 1.570 & 107 & 100641209 & 9 & native language & 188.840 & 6 & 255 \\
\hline 10 & language & 50.460 & 98 & 2850634 & 10 & $\begin{array}{l}\text { english } \\
\text { language }\end{array}$ & 60.950 & 5 & 1035 \\
\hline 11 & but & 1.880 & 93 & 73021662 & 11 & $\begin{array}{l}\text { level of english } \\
\text { proficiency }\end{array}$ & 260.270 & 4 & 1 \\
\hline 12 & they & 1.820 & 89 & 72475819 & 12 & other barrier & 255.940 & 4 & 5 \\
\hline 13 & English & 47.590 & 70 & 2153547 & 13 & different style & 164.450 & 4 & 140 \\
\hline 14 & culture & 39.500 & 66 & 2449121 & 14 & same language & 151.310 & 4 & 173 \\
\hline 15 & speak & 17.680 & 58 & 4829660 & 15 & own language & 139.070 & 4 & 209 \\
\hline 16 & problem & 8.780 & 58 & 9754330 & 16 & $\begin{array}{l}\text { different } \\
\text { pronunciation }\end{array}$ & 195.450 & 3 & 1 \\
\hline 17 & their & 1.410 & 53 & 55459061 & 17 & cultural barrier & 189.970 & 3 & 8 \\
\hline 18 & understand & 10.670 & 45 & 6215980 & 18 & $\begin{array}{l}\text { non-verbal } \\
\text { communication }\end{array}$ & 167.440 & 3 & 41 \\
\hline 19 & time & 1.530 & 45 & 43395654 & 19 & $\begin{array}{l}\text { communication } \\
\text { style }\end{array}$ & 160.460 & 3 & 53 \\
\hline 20 & country & 7.410 & 41 & 8169730 & 20 & group member & 153.190 & 3 & 67 \\
\hline 21 & if & 1.080 & 41 & 55924531 & 21 & $\begin{array}{l}\text { cultural } \\
\text { background }\end{array}$ & 146.880 & 3 & 80 \\
\hline 22 & difference & 16.530 & 35 & 3109618 & 22 & bad mood & 142.410 & 3 & 90 \\
\hline 23 & think & 2.240 & 33 & 21745437 & 23 & big problem & 57.330 & 3 & 576 \\
\hline 24 & like & 1.330 & 32 & 35700205 & 24 & other person & 27.420 & 3 & 1463 \\
\hline
\end{tabular}

Data retrieved and adapted from Sketch Engine Keywords and term extraction tool. Available at https://app.sketchengine.eu/. Keyness score of keywords and key terms is determined through a simple maths method using normalized frequencies per million in the sample and in the reference corpora.

\subsection{Collocation patterns}

The collocation behaviour of the topic words related to perceptions of culture and language barriers in the sample corpus was explored through the Word sketch difference tool for contrasting frequency and score information. The significance test based on the likelihood function measures the co-occurrence typicality (LogDice) of the collocates and the node word based on their frequencies, as well as on the frequency of the collocation as a whole unit. Considering that a G2 higher than 6.6 is significant at $\mathrm{p}<0.01$ and the higher it is the stronger the collocation, it can be concluded that the Word sketch difference data resulted in a stable trend of higher values and stronger language collocations, such as speak a language $(\mathrm{G} 2=12.9)$, language is a barrier $(\mathrm{G}=12.8)$, body language $(\mathrm{G}=12.3)$, use a language $(\mathrm{G}=11.9)$, native language $(\mathrm{G}=11.6)$. Further analysis of culture collocations showed a relatively smaller number of the following items with high collocational strength: culture is a fact $(\mathrm{G}=14)$, culture and/or language (11.4), cultural shock $(\mathrm{G}=11.1)$, cultural contact $(\mathrm{G}=11.1)$. A higher co- 
occurrence typicality range was observed between the same collocate (different, own, other) and each of the nodes such as, culture is different $(\mathrm{G}=12.2)$ and language is different $(\mathrm{G}=11.0)$, own culture $(\mathrm{G}=9.1)$ and own language $(\mathrm{G}=11.2)$, other culture $(\mathrm{G}=10.4)$ and other language $(\mathrm{G}=8.2)$.

\subsection{Corpora comparison}

In order to test Hypothesis 3, the Sketch Engine Compare Corpora tool was used to differentiate between the four sample subcorpora of West Europe (WE), East Europe (EE), Africa and Middle East (AME) and Confucian and Southern Asia (CSA), and two native English corpora, the British Academic Written English Corpus (BAWE) and the English Web Corpus (en Ten Ten 2013). The comparison of data showed the most significant difference between the two subcorpora of AME and CSA (7.13), followed by a difference of 6.80 between CSA and WE, and 6.52 between CSA and EE. Not surprisingly, an anticipated finding suggested a greater difference between CSA and BAWE (6.18), CSA and enTenTen13 (5.48) and BAWE and AME (5.68). Contrary to our expectations, there was a noticeable differentiation of 5.42 between BAWE and WE and a similar value of 5.23 between $\mathrm{WE}$ and enTenTen13. The smallest degree of contrast was seen in the results of EE and enTenTen13 (4.78), EE and BAWE (5.06), and between EE and WE (5.00). In general, CSA demonstrated the most persistent trend towards dissimilarity of all corpora, hence the observed difference between the results provided further support for our Hypothesis 3.

\subsection{Differences in collocation patterns}

For a more elaborate commentary, information about collocation patterns of language/culture was derived from the specialised BAWE corpus, with an absolute frequency of 4,283 and 3,193 of each lemma. The pinpointed examples from academic written texts produced evidence of categories relating culture to society, language, religion, gender, politics, tradition, present, different, organisational, material, Western, shock and status. Language was most commonly associated with discourse, dialect, spoken, body, English, native, programming, acquisition, learning, use, ability, barrier, speak, learn. Some highlights of a more explicit way of expression within the Western group with lower-context traits were found in the association with the process of communication which was seen as transmission of knowledge and information, task orientation was implied through action verbs, including use, control and speak. Decoding of messages seemed more dependent on behaviour and values by the representatives of the Eastern European group with an obvious contrast between own and his culture (only the masculine form was pinpointed) and our and their language with an assumption that different Western habits may affect relationships. A more implicit and formally expressed style of communication 
was demonstrated by participants from Africa and the Middle East groups, associating culture with tradition, nationality, country and value, and a strong awareness of my culture, which was opposed to their language. Confucian and South Asia group demonstrated the strongest high-context orientation to attitude, reflective thinking and appreciation for achievement through studies. The concept of being humble and preserving face implied a more avoiding approach to interaction with other cultures.

\subsection{Discourse prosody}

To provide additional evidence with respect to emotional expression in the discourse, we chose to inspect the semantic prosody of the verb feel, a lexical item with a lower frequency score in the sample corpus, however, intriguing enough to be favourable for a much deeper understanding of the affective aspects of communication challenges. Feel appeared 21 times per million words in the sample corpus, collocating with positive and negative terms, mentioned by total of 17 informants. The sample concordance lines shown in Table 3 indicated a trend to a more neutral discourse prosody with a bigger range of negatively characterised items and fewer co-occurrences bearing positive connotation, nevertheless the overall profile of "feel" as a node word displayed a rather balanced projection of emotional wording in a slightly more positive prosodic direction, due to the higher co-occurrence typicality scores ( $\log$ Dice) of the positive collocates. The strongest language collocations with the highest log likelihood ratio were "comfortable" $(\mathrm{G} 2=12)$; "free" $(\mathrm{G}=11.30)$; "better (English)" $(\mathrm{G}=10.75)$, and "safe" $(\mathrm{G}=10.54)$. Ambiguity and stress indicators were found in "afraid" $(\mathrm{G}=10.91)$; "disconnected", "lazy", "insulted" and "unconfident" $(\mathrm{G}=10.54)$; "confused" and "ignored" $(\mathrm{G}=10.48)$; "shy" and "excluded" ( $\mathrm{G}=10.42)$; not well $(\mathrm{G}=9.79)$.

Table 3. Concordances for "Feel" in the Sample Corpus

\begin{tabular}{|c|c|c|c|}
\hline & & & GDEX \\
\hline $\begin{array}{l}\text { And it helps me because } \\
\text { I am }\end{array}$ & feeling & $\begin{array}{l}\text { that my English is better and better every } d \\
\text { ay. }\end{array}$ & 0.900 \\
\hline $\begin{array}{l}\text { At the beginning of my new } \\
\text { life here I }\end{array}$ & felt & a little bit uncomfortable. & 0.900 \\
\hline $\begin{array}{l}\text { So they do not pay attention } \\
\text { on you and you }\end{array}$ & feel & yourself ignored. & 0.449 \\
\hline I do not know if they & feel & disconnected but they seem like they are. & 0.449 \\
\hline $\begin{array}{l}\text { Well, at first I came } \\
\text { to the VUM. I }\end{array}$ & felt & a little bit afraid of communicating with other & 0.449 \\
\hline I & feel & unconfident to speak in English. & 0.425 \\
\hline $\begin{array}{l}\text { problem with self-study in } \\
\text { the dorm I am }\end{array}$ & feeling & very lazy and sleepy. & 0.400 \\
\hline
\end{tabular}




\begin{tabular}{|c|c|c|c|}
\hline & & & $\mathrm{GDEX}^{*}$ \\
\hline $\begin{array}{l}\text { my worse level of English } \\
\text { makes me }\end{array}$ & feel & myself shy. & 0.400 \\
\hline It will create a conflict if I & feel & that you are ignorant in how you view Africa & 0.400 \\
\hline $\begin{array}{l}\text { I am talking with the guy } \\
\text { from Egypt I am }\end{array}$ & feeling & confused. He is talking really fast. & 0.375 \\
\hline I have experienced that as I & feel & comfortable to speak about new things that & 0.361 \\
\hline $\begin{array}{l}\text { Working with teachers is } \\
\text { nice but I }\end{array}$ & feel & $\begin{array}{l}\text { comfortable only in Business } \\
\text { communication }\end{array}$ & 0.350 \\
\hline $\begin{array}{l}\text { everyone spoke fluent } \\
\text { English and I }\end{array}$ & felt & not really well in the beginning because I did & 0.337 \\
\hline $\begin{array}{l}\text { they do not care that others } \\
\text { may }\end{array}$ & feel & uncomfortable in such situation. & 0.319 \\
\hline $\begin{array}{l}\text { instead of using English so } \\
\text { others can }\end{array}$ & feel & excluded from the connection. & 0.259 \\
\hline $\begin{array}{l}\text { sometimes our foreign } \\
\text { colleagues }\end{array}$ & feel & $\begin{array}{l}\text { insulted because the body signs have } \\
\text { different }\end{array}$ & 0.254 \\
\hline $\begin{array}{l}\text { more than two-month } \\
\text { studying in VUM I }\end{array}$ & feel & $\begin{array}{l}\text { the barriers and differences of communicat } \\
\text { ion. }\end{array}$ & 0.149 \\
\hline $\begin{array}{l}\text { I am open to new } \\
\text { friendships, but I }\end{array}$ & feel & $\begin{array}{l}\text { more comfortable, talking to the people with } \\
\text { similar }\end{array}$ & 0.129 \\
\hline $\begin{array}{l}\text { overcome in an easy way } \\
\text { because people }\end{array}$ & feel & $\begin{array}{l}\text { safe when they trust somebody, except if } \\
\text { they do }\end{array}$ & 0 \\
\hline $\begin{array}{l}\text { we all transmitted our } \\
\text { thoughts and ideas }\end{array}$ & feeling & $\begin{array}{l}\text { free to share them with the group and the } \\
\text { leader }\end{array}$ & 0 \\
\hline
\end{tabular}

*GDEX score exhibits frequent and well-dispersed patterns of use with the highest density in the context (Kilgarriff, A., Husák, M., McAdam, K., Rundell M. \& Rychlý P., 2008). Data retrieved and adapted from Sketch Engine https://app.sketchengine.eu/

\section{Discussion}

The quantitative tests results and their analysis provided a significant evidence of a perception trend towards differences in verbal and non-verbal aspects of language, in which language was seen as an important barrier associated with English as a means of communication. Being able to express oneself freely in multicultural environment puts the speaker in control of the communication process and helps to build a positive self-concept (Rubio, 2007), conversely, the lack of adequate language skills can make the speaker feel helpless and endangered, therefore, appropriate use of English as an important ability to make and communicate meaning in spoken and written contexts becomes an instrument for imposing power and self-assertion within the group, hence explanation of the present results seems consistent with Barna's model of stumbling blocks in ICC. Differences in language, expressed through vocabulary, idiomatic concepts and pronunciation, in this case, are identified as the second communication 
block by Barna, which in contrast to the unconscious assumption of similarity for example, seems to be attributed with clear self-awareness of the problem and its consequences on mutual understanding. It should be here emphasised that language barrier, according to Barna, tends to be centrally focused and perceived as the main communication barrier by communication participants in intercultural environment, especially in the early stage of intercultural encounters, as is the case of the present research. It is important to note that body language was perceived as the most frequent term related to misunderstanding in comparison to language and perceptions of culturally different identities. The latter appeared less differentiated than the perceptions of language differences with some lower indication of awareness of time, religion and otherness. However, as argued by Barna, cultural background affects in different ways people's perception of the surrounding world, thus influencing their nonverbal reference to what is being seen, felt, smelt or heard, so the nonverbal misinterpretation block seems to be as significant as language differences, which was also proved by the present experimental evidence. Despite the limited period of intercultural exchange, the students had obviously managed to develop some sensitivity to more subtle cues in the environment, likely due to the informal communication outside the classroom and the content integrated class activities. Overcoming the observed lack of awareness of subtle barriers associated with the expression of concepts of space, stereotyping, prejudice and tendency to evaluate requires a more informal learning environment, according to Barna, therefore, it could be conceivably suggested that there should be raised a concern over nonverbal misinterpretations in the Westernised education environment of EMI, especially when provided in non-native English speaking countries, where traditionally a more formal style of communication is established. Some important conclusions emerged from corpora comparison with BAWE, which suggested that similarity of perceptions between native speakers and non-native speakers of English can be sought in the attitudes to the differences in the use of language, speaking skills, body language, avoiding direct conflict, association with the group and more conservative traditions. On the other hand, several considerable differences were revealed between the two corpora, mainly in terms of social, gender, political and organisational attitudes which were not detected in the sample corpus. It is noteworthy to mention here that English as a tool for socialisation, according to Scollon, Scollon, and Jones (2012, p. 17) carries in itself "Western patterns of discourse, which ultimately lead to confusion or to misinterpretation in intercultural discourse ... transmitted through the process of the teaching and learning of English". Furthermore, there has been an established media trend towards inflicting European identities as a white norm associated with perceptions of dominance, as argued by Cheshmedzhieva-Stoycheva (2018, p. 43). In other words, it seems that these may imply a contradicting viewpoint of English as a means of communication and learning, and at the same time as a 
means of exerting cultural influence through its low-context Western patterns of discourse.

Comparison of the subcorpora with BAWE and to each other illustrated significant communication challenges for the CSA group, which demonstrated strongest high-context orientation and conformity to group values and group appreciation, followed by the AME group with strong family attachment and group belonging. The Eastern European group results suggested more similarity with BAWE rather than with the Western European group, which may refer to the observed differences in the higher level of their proficiency in written English. Taken together, the overall profile of the discourse participants is family and group oriented, with different degree of unequally distributed power in their society and fixed social roles, functioning in a south-east European physical environment which is intolerant to changes and innovation and using a communication tool, belonging to a more gender equality and less power hierarchy social system. Such a complicated interdiscourse communication system suggests a process of interaction between members of different groups which often involves conflicting expressions of multiple identities leading to miscommunication. An intriguing interdiscourse aspect discussed by Scollon et al. (2012) takes into account the ambiguous nature of language, spoken or written, which makes people speculate about the real meaning of messages. Speculation is based on the source language and personal views of reality, and understanding does not depend on knowledge of grammar or vocabulary but on inherent presumptions fixed in established discourse systems. Generally speaking, it is not the incorrect grammar or mispronunciation which distort communication but differences in discourse patterns. Being deeply rooted in the culture, preconceptions and stereotypes tend to influence our perceptions, acting as stumbling blocks which can distort communication in the classroom. The tendency to evaluate and make emotional judgements about what is right or wrong affects fair and unbiased comprehension in interaction with people in an unfamiliar multicultural environment, which increases the associated feelings of anxiety and uncertainty, affecting in turns cognitive functions and academic performance.

\section{Conclusions}

In response to the first research question, this study has found that communication challenges in the multicultural classroom are most commonly perceived by the international students as different levels of English proficiency, pronunciation, native language, language misunderstanding, cultural background and communication styles. The quantitative and qualitative analyses supported the three hypothetical statements made by the author. The results provided evidence of an unanticipated finding indicating that body language had a slightly more significant impact on the undergraduates' perceptions than verbal 
language. These results can be explained through the understanding that both verbal and non-verbal language seem to be attributed with clear self-awareness of the problems and their consequences on communication outcomes. Another explanation could be linked to the cognitive load associated with learning through EMI which in previous research was found to add a further linguistic challenge, tension and negative impact on self-confidence. This study also confirmed that perceptions of barriers associated with assumption of similarity, stereotyping, tendency to evaluate and cultural shock have a less significant effect on students' perceptions of communication barriers due to their unconscious nature and lower degree of critical cultural awareness. Perceptions of language differences and cultural ambiguity and expectations for communication barriers were found to be most significantly expressed by international students from Confucian and Southern Asia raised and educated in higher context cultures sharing values of collectivism, hierarchical relationships and maintaining face. In response to the second research question of this study, it can be concluded that the individualistic Western patterns of discourse carried in English, are likely to be in contrast with students' expectations for more formal expression of the Self and distribution of educational roles in all the subgroups of the sample. The emerging consequences of communication issues on academic performance seem to be associated with a various degree of negative impact on relationships between students and teachers, students' expectations for group work, approach to independent study, perceptions of time and practical approach to classroom activities. The current study was limited by the smaller size of the corpus collected from student's essays written in formal environment and within a limited time. Another limitation was related to the unequal number of informants in the four subcorpora, due to the fewer number of representatives from some nationalities. As students from higher-context societies might have restrained from expressing potential negative emotions, a further study could attempt at assessing the association of Uncertainty avoidance with levels of anxiety and stress in EMI. It would be also interesting to compare levels of intercultural communication competence between students from different cultural groups.

\section{Implications for practice}

An important implication is that feelings of uncertainty and anxiety are more likely to arise from miscommunication due to differentiation in international students' perceptions of language expression through phonology, meaning of words, relationship between students and teachers, expected formality, selfexpression and learning priority, different concept of time and expectations for more controlled or independent learning (Witsel, 2003). Contrasting perceptions of achievement orientation, belonging to a group and work regulation can also have a strong negative impact on the verbal and non-verbal communication process, 
consequently building communication barriers in educational environment (Thomas, 1995). Therefore, an apparent answer to our third research question and another important implication which could be made for developing strategic competence in international students is that professionals involved in teaching and learning in EMI should accept language as a culture code and a biologically innate means of communication (Kroeber and Kluckhohn, 1952) with the purpose of developing awareness and understanding of English as a significant reason for communication failure caused by hindrances arising from more demanding areas of academic studies, which require active verbal expression, critical thinking, practical training, use of technology, group presentation and discussions, academic writing, problem solving and following task instructions. A communicative approach for developing ICCC through "Knowledge, motivation and skills to interact effectively and appropriately with members of different cultures" (Wiseman, 2002, p. 208) should be adopted by educators to facilitate a learning environment encouraging active participation in class communication and allowing students to coordinate their verbal and non-verbal expression in order to achieve particular social and personal communication goals, in compliance with the situational norms. Since uncertainty is considered a fundamental cognitive category, it can negatively affect one's ability to predict and explain different types of behaviours which leads to anxiety. Mindful efforts to understand others will help to maintain an optimum level of uncertainty and anxiety in order to establish effective communication (Gudykunst, 2005). To promote ICCC, Anglophone universities should integrate intentional pedagogical approaches facilitating the ICCC skills and knowledge building through selfreflection, experiential learning, anthropological research and visualisation, relevant theoretical courses, in-class activities encouraging reflective and critical thinking, adequate teacher training and active teachers' engagement in tailoring and applying the learning and teaching practice as well as adequate evaluation and assessment (Leavitt, Wisdom, \& Leavitt, 2017).

\section{References:}

Bachman, L. F., \& Palmer, A. S. (2010). Language Assessment in Practice. Oxford: Oxford University Press.

Barna, L.M. (1994). Stumbling blocks in intercultural communication. In L.A. Samovar \& R.E. Porter (Eds.), Intercultural Communication: A Reader (pp. 337-346). Belmont, CA: Wadsworth Inc.

Bhatia, V. K., Flowerdew, J., \& Jones, R. H. (2008). Approaches to discourse analysis. In Advances in discourse studies (pp. 11-28). London and New York: Routledge.

Biber, D. (2006). University language : A corpus-based study of spoken and written registers. Retrieved from https://ebookcentral.proquest.com

Biber, D., Conrad, S., \& Reppen, R. (1998). Corpus linguistics. Cambridge: Cambridge University Press. 
Björkman, B. (2017). So You Think You Can ELF: English as a Lingua Franca as the Medium of Instruction. HERMES - Journal of Language and Communication in Business, 23(45), 77-96. https://doi.org/10.7146/hjlcb.v23i45.97348

Byram, M., Nichols, A., \& Stevens, D. (2001). Developing intercultural competence in practice. Clevedon: Multilingual Matters.

Canale, M., \& Swain, M. (1980). Theoretical Bases of Communicative Approaches to Second Language Teaching and Testing. Applied Linguistics, 1(1).

Celce-Murcia, M., Dornyei, Z., \& Thurrell, S. (1995). Communicative Competence: A Pedagogically Motivated Model with Content Specifications. Issues in Applied Linguistics, 6(2).

Chang, Y. Y. (2010). English-medium instruction for subject courses in tertiary education: Reactions from Taiwanese undergraduate students. Taiwan International ESP Journal, 2(1), 53-82.

Cheshmedzhieva-Stoycheva, D. (2018). Framing Muslims in the Bulgarian and the British Media Discourse. Shumen: Konstantin Preslavsky University Press.

Coleman, J. (2006). English-medium teaching in European higher education. Language teaching, 39(1), 1-14.

Dearden, J. (2014). English as a medium of instruction-a growing global phenomenon [PDF file]. British Council. Retrieved from https://www.britishcouncil.org/sites/default/files/ english_as_a_medium_of_instruction.pdf

Evans, S., \& Morrison, B. (2011). Meeting the challenges of English-medium higher education: The first-year experience in Hong Kong. English for Specific Purposes, 30(3).

Gee, J. (2010). How to do discourse analysis a toolkit. London UK: Routledge. Retrieved from https://www.dawsonera.com/readonline/9780203850992

Gee, J. \& Handford, M. (2012). The Routledge Handbook of Discourse Analysis. London, UK: Routledge.

Gudykunst, W. (2005). Theorizing about intercultural communication. Thousand Oaks, London: Sage Publications.

Hall, E. T. (1966). The Hidden dimension. Garden City, N.Y: Doubleday.

Hall, E. T. (1977). Beyond culture. New York: Anchor Books.

Handford, M. (2014). Cultural identities in international, interorganisational meetings: a corpus-informed discourse analysis of indexical we. Language and Intercultural Communication, 14(1), 41-58.

Handford, M. (2015). Corpus Analysis. In Z. Hua, (Ed.), Research methods in intercultural communication. A practical guide (pp.27-44). Retrieved from https://ebookcentral.proquest.com

Hofstede, G. (1980). Culture's consequences. Beverly Hills, Sage Publications.

Hofstede, G. (1986). Cultural differences in teaching and learning. International Journal of Intercultural Relations, 10(3), 301-320.

House, R. J., Hanges, P. J., Javidan, M., Dorfman, P. W., \& Gupta, V. (2004). Culture, Leadership, and Organizations: The GLOBE Study of 62 Societies. Sage Pu, Thousand Oaks, CA: Sage Publications. 
Jensen, C., Denver, L., Mees, I. M., \& Werther, C. (2013). Students' attitudes to lecturers' English in English-medium higher education in Denmark. Nordic Journal of English Studies, 12(1), 87-112.

Kilgarriff,A., Husák, M., McAdam,K., Rundell M.\& RychlýP.(2008). GDEX: Automatically finding good dictionary examples in a corpus. In Proceedings of the 13th EURALEX International Congress. Spain, July 2008, 425-432.

Kroeber, A. \& Kluckhohn, C. (1952). Culture, a Critical Review of Concepts and Definitions. Cambridge. Peabody Museum of American Archeology and Ethnology, Harvard University, [PDF file] XLVII(1). Available at: http://www.pseudology.org/Psyhology/ CultureCriticalReview1952a.pdf

Leavitt, L., Wisdom, S., \& Leavitt, K. (Eds.). (2017). Cultural awareness and competency development in higher education. IGI Global.

Marcus, M., Santorini B. \& Marcinkiewicz, M., A. (1993). Building a large annotated corpus of English: The Penn Treebank. In Computational Linguistics, volume 19, number 2.

McEnery, T.\& Hardie, A. (2012). Corpus linguistics. Cambridge: Cambridge University Press.

Moreno, A.I. (2008). The importance of comparable corpora in cross-cultural studies. In U. Connor, E. Nagelhout \& W. Rozycki (Eds), Contrastive Rhetoric: Reaching to Intercultural Rhetoric (pp. 25-41). Amsterdam: John Benjamins.

Nedelcheva, S. (2017). Crossing Borders On The Balkan Route: Representation Of Migration In Online News. Studies in Linguistics, Culture, and FLT, 2(1), 53-70.

O'Keeffe, A., \& Adolphs, S. (2008). Response tokens in British and Irish discourse: Corpus, context and variational pragmatics. In K. Schneider \& A. Barron (Eds), Variational Pragmatics: A Focus on Regional Varieties in Pluricentric Languages (pp.69-98). Amsterdam: John Benjamins.

Rubio, F. (2007). Self-esteem and foreign language learning. Newcastle, UK: Cambridge Scholars Pub.

Scollon, R., Scollon, S. W., \& Jones, R. H. (2012). Intercultural communication : A discourse approach. Retrieved from https://ebookcentral.proquest.com

Seidlhofer, B., Breiteneder, A., \& Pitzl, M. (2006). English As A Lingua Franca In Europe: Challenges For Applied Linguistics. Annual Review of Applied Linguistics, 26, pp. 3-34. doi:http://dx.doi.org.ezproxy.cardiffmet.ac.uk/10.1017/S026719050600002X

Sketch Engine (2019). Copyright Lexical Computing CZ s.r.o. Available at http://www. sketchengine.eu

Thomas, J. (1995). Meaningin interaction: An introduction to pragmatics. London: Longman.

Ting-Toomey, S., \& Chung, L. C. (2012). Understanding intercultural communication (2nd ed.). Los Angeles, CA: Roxbury Press.

Ting-Toomey, S., \& Dorjee, T. (2019). Communicating Across Cultures (2nd ed.). New York: Guilford Publications.

Todorova, R. (2017). Metaphoric Transfer Of Knowledge, Cultural Experiences And Social Practices In English Language Advertising Discourse. Studies in Linguistics, Culture, and FLT, 2(1), 29-39. 
Wilkinson, R. (2013). English-medium instruction at a Dutch university: Challenges and pitfalls. In A. Doiz, D. Lasagabaster, \& J.M. Sierra, (Eds.), English-Medium Instruction At Universities: Global Challenges (pp. 3-24). Clevedon, UK: Multilingual Matters.

Wiseman, R.L. (2002). Intercultural communication competence. In B. Mody \& W. B. Gudykunst (Eds), Handbook of international and intercultural communication (pp.207224). Thousand Oaks, California: Sage Publications.

Witsel, M. (2003). Teaching and learning issues in the multicultural classroom. School of Tourism and Hospitality Management Papers. ETL Conference, Queensland College of Art, Griffith University. 